\title{
Do Nonhuman Primates Ascribe Goals to the Choices of Conspecifics?
}

\author{
Laurent Prétôt ${ }^{1,2, *}$, Daniel J. Weiss ${ }^{3}$, and Sarah F. Brosnan ${ }^{1,2,4}$ \\ ${ }^{1}$ Department of Psychology, Georgia State University, Atlanta, GA, U.S.A. \\ ${ }^{2}$ Language Research Center, Georgia State University, Atlanta, GA, U.S.A. \\ ${ }^{3}$ Department of Psychology, Pennsylvania State University, University Park, PA, U.S.A. \\ ${ }^{4}$ Department of Philosophy \& Neuroscience Institute, Georgia State University, Atlanta, GA, U.S.A. \\ *Corresponding author (Email: laurent.pretot@gmail.com)
}

Citation - Prétôt, L., Weiss, D. J., \& Brosnan, S. F. (2018). Do nonhuman primates ascribe goals to the choices of conspecifics? Animal Behavior and Cognition, 5(1), 41-54. https://doi.org/10.26451/abc.05.01.04.2018

\begin{abstract}
Numerous studies have investigated the extent to which nonhuman primates understand the goals of a partner. One limitation common to many of these studies, however, has been that animals are often required to interpret actions of heterospecifics, typically human experimenters. In this study, we tested capuchin monkeys' understanding of goal-directed actions by examining whether they would choose similarly after watching a volitional versus forced choice by a conspecific. In the task, a model subject chose between two different objects in view of a focal subject, after which the focal was presented with the same choice. In the Free Choice condition, the two objects were at equal distance and within reach of the model, whereas in the Limited Choice condition, one object was placed out of the model's reach. In Study 1, using objects that differed in material, size, shape and color, monkeys showed little evidence of copying the partner in the Free Choice condition; however, they chose the different object more often in the Limited Choice relative to the Free Choice condition. To try to rule out that these results were due to a preference for some feature of the objects, in Study 2, the objects differed only in color and pattern. Although subjects did not copy the partner more in the Free Choice condition, some showed, as in Study 1, a preference for the different object in the Limited Choice condition. These results weakly support the hypothesis that monkeys perceive volitional actions in a social learning context, in that individuals adapted their behavior based on the partner's choice in the task. We discuss the implications of the 'failure' to select the same object as the conspecific in the task.
\end{abstract}

Key Words: Intentionality, Choice task, Observational learning, Social influence, Nonhuman primates, Cebus [Sapajus] apella

Theory of mind is a set of specific cognitive abilities that involves the attribution of mental states to others (Premack \& Woodruff, 1978). Among these cognitive capacities, understanding others' intentional actions (or intentions) is already present very early in childhood (see Tomasello, Carpenter, Call, Behne, \& Moll, 2005, for a review). For example, 6-month old infants understand other's actions as object-directed (e.g., Woodward, 1998, 1999). By 9- to 12 months of age, infants are capable of understanding the basics of goal-directed actions (e.g., Baldwin, Baird, Saylor, \& Clark, 2001), including understanding unsuccessful actions, such as intended actions (e.g., Gergely, Nadasdy, Csibra, \& Biro, 1995), versus accidental actions (e.g., Behne, Carpenter, Call, \& Tomasello, 2005). By 14 months, children begin to understand advanced intentional actions, including choosing action plans (e.g., 
Buttelmann, Carpenter, Call, \& Tomasello, 2008; Gergely, Bekkering, \& Kiraly, 2002; Tomasello \& Haberl, 2003).

Recent evidence supports the view that this trait may not be unique to humans, and that other highly social species, such as birds (e.g., Bugnyar \& Kotrschal, 2004; Péron, Rat-Fischer, Nagle, \& Bovet, 2010), dogs (Marshall-Pescini, Ceretta, \& Prato-Previde, 2014) and other primates (e.g., Call \& Jensen, 2007; Rosati, Hare, \& Santos, 2010; Tomasello \& Call, 1997; Tomasello, Call, \& Hare, 2003), also have the capacity to understand others' intentions, at least to some degree. However, many of these studies have shown mixed results. Supporting the hypothesis, chimpanzees, Tonkean macaques and capuchin monkeys appeared to understand when an experimenter tried but was unable to give food as compared to when the experimenter did not want to share (Call, Hare, Carpenter, \& Tomasello, 2004; Canteloup \& Meunier, 2017; Phillips, Barnes, Mahajan, Yamaguchi, \& Santos, 2009). However, while chimpanzees, orangutans, rhesus macaques and cotton-top tamarins, seemed to understand the difference between a human's intended and accidental actions (Call \& Tomasello, 1998; Wood, Glynn, Phillips, \& Hauser, 2007), Tonkean macaques, capuchins, and another population of chimpanzees did not when tested in a similar paradigm (Costes-Thiré et al., 2015; Povinelli, Perilloux, Reaux, \& Bierschwale, 1998). These behaviors are apparently sensitive to context too; two recent studies showed that chimpanzees, bonobos, and orangutans appeared to distinguish true from false beliefs (Buttelmann, Buttelmann, Carpenter, Call, \& Tomasello, 2017; Krupenye, Kano, Hirata, Call, \& Tomasello, 2016), whereas all three species failed to show evidence in previous studies (Call \& Tomasello, 1999; Kaminski, Call, \& Tomasello, 2008; Krachun, Carpenter, Call, \& Tomasello, 2010; but see Krachun, Carpenter, Call, \& Tomasello, 2009, for mixed results).

One explanation for these discrepancies is that the presence or actions of the experimenter is influencing behavior. Although there are certainly exceptions (see Burkart, Kupferberg, Glasauer, \& van Schaik, 2012; Emery, Lorincz, Perrett, Oram, \& Baker, 1997; Hare, Call, Agnetta, \& Tomasello, 2000; Kupferberg, Glasauer, \& Burkart, 2013; Tomasello, Call, \& Hare, 1998), many of these comparative studies require animals to interpret actions of heterospecifics, typically human actors. However, recent studies indicate that subjects may do better when copying conspecific models; for example, cockatoos and chimpanzees learned to solve a tool-use task only with a live conspecific demonstrator (Auersperg et al., 2014; Hopper, Lambeth, Schapiro, \& Whiten, 2015), emphasizing the importance of witnessed agency in social learning. Indeed, given the extent to which we have learned about great apes by studying how they react to conspecifics (i.e., in false belief tasks), a logical next step was to import this to monkeys. Specifically, we chose to examine whether monkeys would perceive volitional actions in the context of a social learning task.

For this study, we tested capuchin monkeys (Cebus [Sapajus] apella) for several reasons. First, capuchins are generalist extractive foragers (they are specialized in processing embedded foods such as hidden insects and hard-shelled fruits; see Fragaszy, Visalberghi, \& Fedigan, 2004; Reader, Hager, \& Laland, 2011) and are thus likely to benefit from watching others in order to improve their foraging skills (Perry, 2011). Second, capuchins are one of the best-studied primate species with regard to the issue of social learning in food contexts (Fragaszy et al., 2004; Perry, 2011), so we know quite a lot about which cues are important to them. For example, Visalberghi and Addessi $(2000,2001)$ found that monkeys were more likely to approach novel foods in the presence of foraging conspecifics, but they did not pay attention to the specific properties of the foods (e.g., color) eaten by others; instead, the authors suggest that social cues increase acceptance of novel foods or are used to synchronize feeding activities. Third, more recent studies on captive capuchins have found evidence of effects of observation on skill acquisition in a food procurement context (Dindo, Thierry, \& Whiten, 2008; Dindo, Whiten, \& de Waal, 2009). In these studies, a demonstrator (higher-rank) was trained to open an artificial fruit in one of two ways prior to playing the role of model for a conspecific (lower-rank). Importantly, the dyads consisted of individuals that shared high levels of tolerance and affiliative behavior. In the task, the observer preferentially adopted the same foraging technique as the model, indicating that the quality of social relationship is likely to play a role in the desire to copy other capuchins (also see Brosnan \& de Waal, 2004; de Waal \& Bonnie, 2009). Finally, there are only a few studies of capuchins' ability to understand 
goal-directed actions, and the results thus far are not uniform (e.g., Drayton \& Santos, 2014; Drayton, Varman, \& Santos, 2016). Therefore, it is important to further investigate this capacity in a different context.

In the current study, we used a novel paradigm to explore whether capuchins understand goaldirected actions in a social learning context. In the task, a focal capuchin monkey could see a conspecific model select one of two different non-food objects, after which the focal subject was presented the same choice. Importantly, we were interested in the monkeys' spontaneous choice in the task; therefore, both models and subjects could choose freely between the two objects (i.e., the model was not trained in one choice or the other). In addition, neither the models nor the subjects received any food reward during the trials, which minimized the impact of food visibility or receipt on monkeys' decisions. Subjects were tested in two conditions: in the Free Choice condition, both objects were immediately accessible to the model, whereas in the Limited Choice condition, one object was immediately accessible and the other was placed beyond the reach of the model and was therefore never accessible. Subjects, who had full access to both objects in both conditions, then chose one for themselves.

We anticipated that, if the subjects understood, at least to some degree, how volitional actions are produced, they should recognize that the model freely chose from between the two choices in the Free Choice condition, but had no real choice in the Limited Choice condition because one of the objects was out of reach. We also assumed, based on previous social learning work, that subjects prefer to copy conspecific models (e.g., Brosnan \& de Waal, 2004; de Waal \& Bonnie, 2009; Dindo et al., 2008; 2009). Therefore we generated two predictions. First, we predicted that the focal subject would preferentially choose the same object as the model in the Free Choice condition. We had no directional prediction about their behavior in the Limited Choice condition, because there was no a priori reason for the subjects to make a decision one way or the other based on the model's restricted access. Consequently, our second prediction was that they would make the same choice as the partner more frequently in the Free Choice condition than in the Limited Choice condition, because there was a reason to assume that the model made an intentional selection (thereby expressing an actual preference) in the Free Choice condition.

\section{General Methods}

\section{Subjects and Housing}

We tested 11 captive-born brown capuchin monkeys (Cebus [Sapajus] apella) from two stable social groups (Group A: 2 males, average age $=20$ years, range $=16-23$ years; 3 females, average age $=$ 11 years, range $=5-16$ years; Group B: 4 males, average age $=10$ years, range $=6-15$ years; 2 females, average age $=14$ years, range $=11-17$ years) at the Language Research Center of Georgia State University, Atlanta, Georgia, USA. One female subject often chose not to participate (i.e., did not enter the testing area on more than half of the opportunities that she had to do so) and so was dropped from testing, resulting in a sample size of 10 individuals. Prior to this study, all of our subjects had participated in studies that involved exchanging objects with an experimenter (e.g., Brosnan et al., 2011; Evans, Beran, Paglieri, \& Addessi, 2012). Subjects were always housed with their social groups except when they separated voluntarily for non-invasive behavioral and cognitive testing.

The monkeys lived in mixed-sex social groups in two large indoor/outdoor enclosures. Each enclosure contained ample three-dimensional climbing space as well as trapezes, perches and enrichment items. Subjects had been co-housed in their social groups for many years, and in some cases their entire lives, so the models were always very familiar individuals with whom the subjects had a long history. The enclosure for each social group was divided into an indoor area and a larger outdoor area (approximately one-half to two-thirds of their total space). The subjects had previously been trained to voluntarily enter testing boxes attached to their indoor area, which allowed us to separate individuals from their group for testing. They could choose not to participate at any time by walking away from the experimenter, and there were no consequences for the monkeys if they decided not to participate. No subject was ever involved in more than one session of this test on any given day. 
Subjects were fed a diet according to their species-specific needs that included primate chow and fresh fruits and vegetables. They also received enrichment foods several times per day. Animals were never deprived of food or water for testing purposes and received the same diet, with food provisioning at the same times of day, regardless of participation in this experiment. Running water was available ad libitum, including during testing. All of the capuchin monkey experiments were approved by the Georgia State University IACUC (A12015) and met the ethical standards of the United States and the American Society of Primatologists. Georgia State University is fully accredited by AAALAC.

\section{Study 1}

\section{Procedure}

Subjects were tested in pairs consisting of a model and a focal individual. The focal and model were adjacent to one another in a large testing cage, separated by a clear barrier that gave them visual access to the partner (see Figure 1). Because we were primarily interested in the aggregated group performance, each subject played both roles, and we tested all possible combinations of pairs (regardless of their social rank or relatedness). In this study, monkeys were presented PVC and metallic hardware objects differing in various aspects such as size, shape, and color (see Figure 2). The objects were all novel to the subjects, and we did not conduct any preference tests prior to this experiment in order to minimize the impact of exposure on the subjects' decisions. In this study, we looked at whether the focal subject chose the same object (labeled as 'same') or the different object (labeled as 'different') as the model subject.

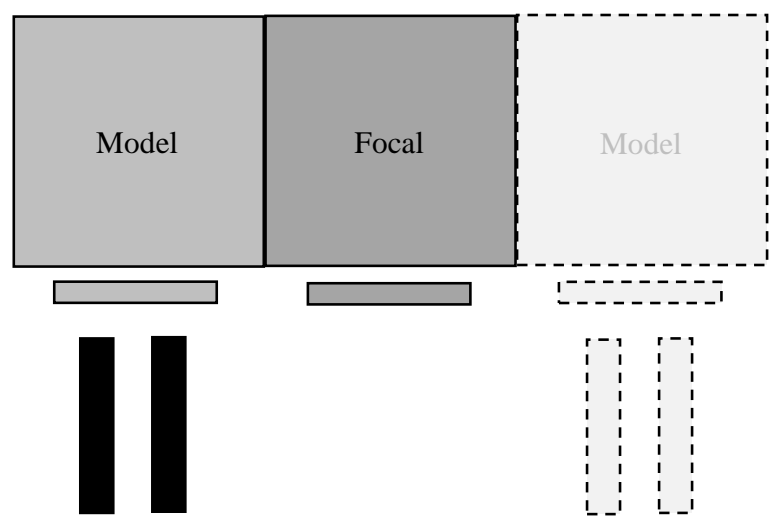

Figure 1. Top view of the testing area and experimental set-up. The model could choose between two different objects, each one placed on an identical black tray. The focal individual could watch their choice from a small test chamber adjacent to the subject before being presented with the same choice. Depending on the location of each individual, the presentation of the objects to the model occurred either on the right or left side of the focal.

Choices were made using a choice apparatus designed by Salwiczek et al. (2012; see Figure 3). This apparatus was attached to the front of the monkey's test box and was designed to limit the monkey to a single choice. It consisted of two trapdoors fastened by Velcro, attached to each other by a string that worked in a drawbridge-like fashion; that is, one door pulled closed when the other was pushed open (for further detail, see Salwiczek et al., 2012). A choice was made once the subject grasped one of the two objects, which could subsequently be returned to the experimenter. 


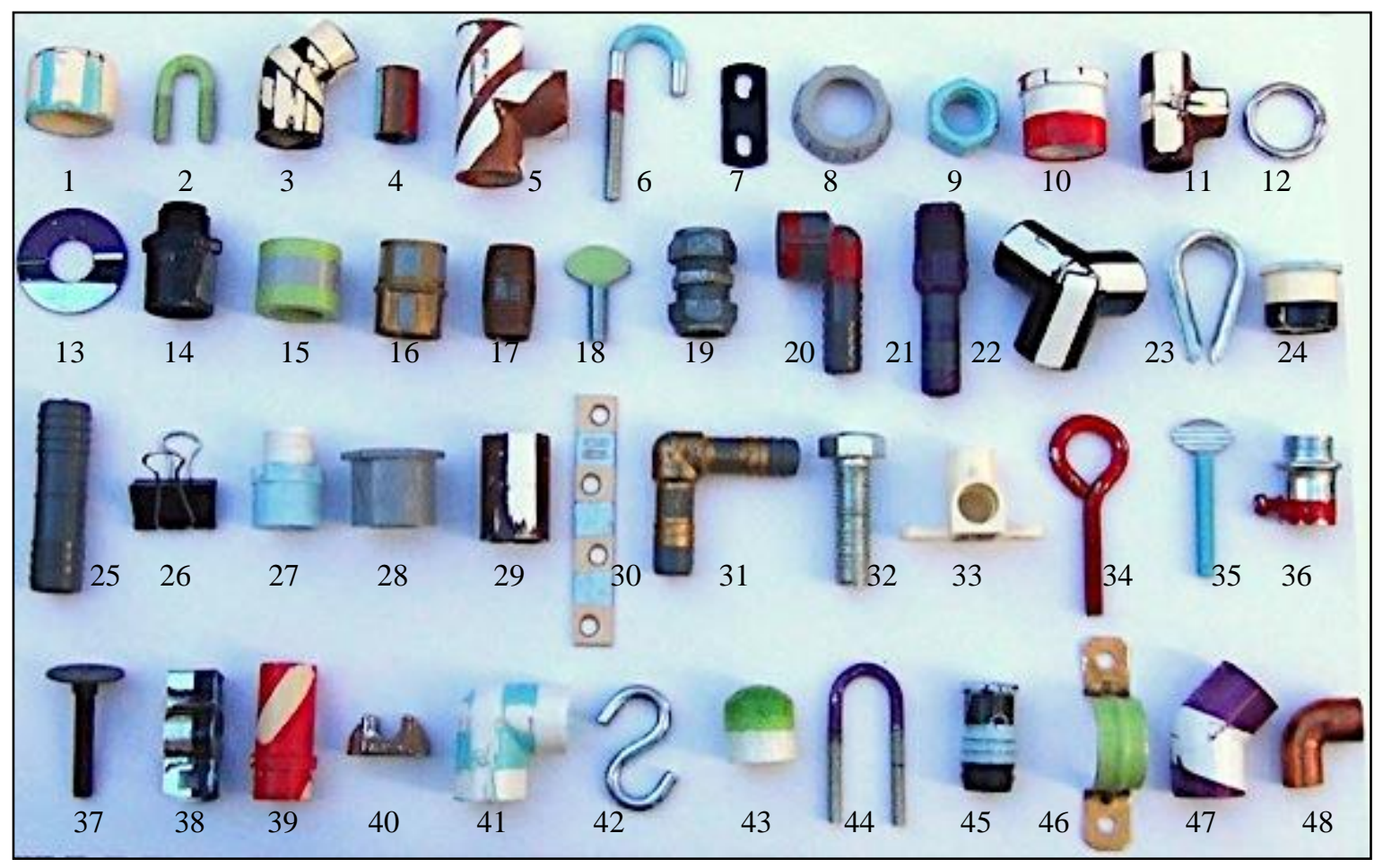

Figure 2. Set of hardware objects used in Study 1. There were 24 items for each category (PVC or metallic). In details, PVC objects: 1, 3, 5, 8, 10, 11, 14, 15, 16, 20, 21, 22, 24, 25, 27, 28, 29, 31, 33, 39, 41, 43, 45, 47. Metallic objects: 2, 4, 6, 7, 9, 12, $13,17,18,19,23,26,30,32,34,35,36,37,38,40,42,44,46,48$. See Supplemental Material for details on object combinations and experiment results.

During the task, the focal individual could watch the model choose between two different objects, each placed on an identical black tray (Figure 1). A trial began once the model was presented with the trays carrying the tokens. Following the model's choice, the unselected object was removed from the tray and placed out of sight of the monkeys (into the experimenter's pocket). The model then returned the object to the experimenter, who placed it out of sight with the other object. The experimenter then rebaited the two trays out of sight and the focal individual was presented with the same choice. As with the model, the focal individual could pick up one of the two objects and return it to the experimenter, after which the trial ended. Note that subjects experienced each pair of objects only once. In addition, the model and the focal were given the same food reward (one grape each) only at the end of a trial, which maintained subjects' motivation to participate in the task while reducing the risk that the focal subjects associated the food reward with the object. Food was kept out of sight of the subjects at all times. All but one subject always returned the chosen object to the experimenter.

There were two conditions, which differed in whether the model could access one or both objects. This was done to determine whether the focal took into account that the model could (or could not) reach one of the objects. In both conditions, one object (randomly assigned) was placed on each tray. In the Free Choice condition, the two objects were located within reach (approximately $10 \mathrm{~cm}$ from the testing area; Figure 3) and at equal distance from the model, while in the Limited Choice condition, one object was out of reach (approximately $40 \mathrm{~cm}$ from the testing area) while the other object was $10 \mathrm{~cm}$ from the testing area. Consequently, the model always chose the within-reach object in the Limited Choice condition. In both conditions, after watching the model make a choice, the focal was presented with both objects in reach and at equal distance (as in the Free Choice condition). Note that the trapdoors of the choice apparatus were never blocked at any time, regardless of condition. 

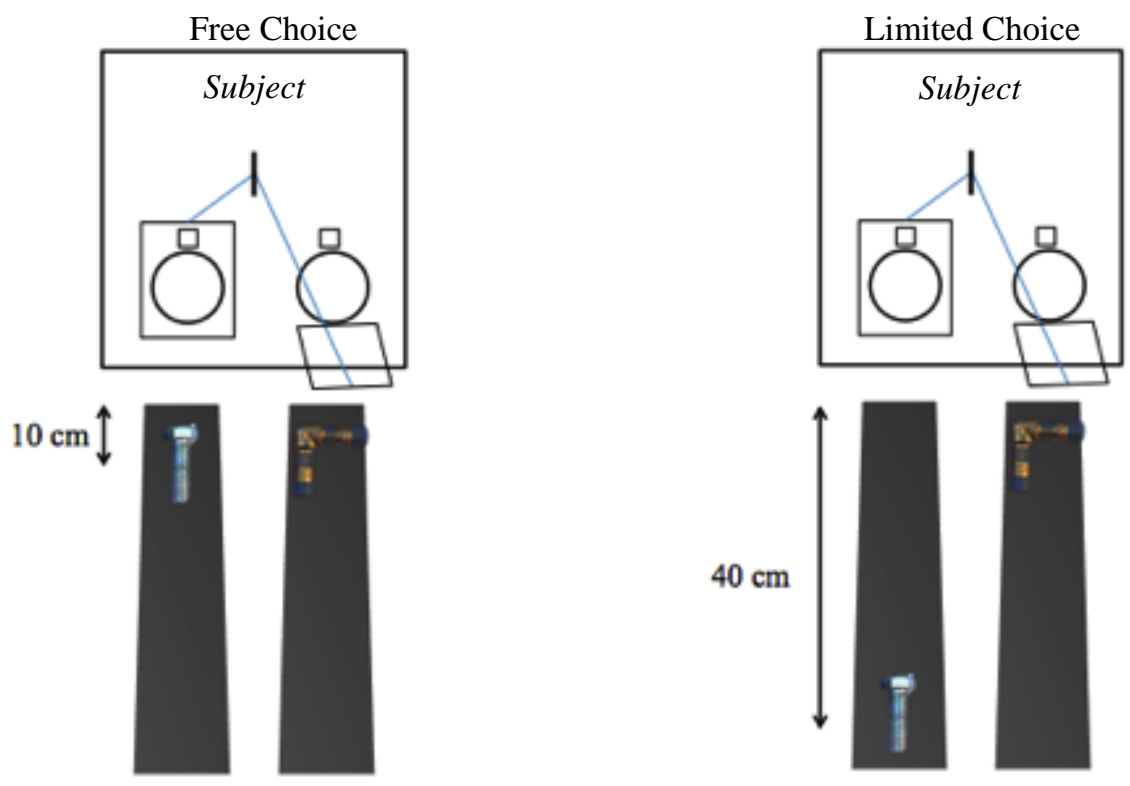

Figure 3. Experimenter's view of the choice presentation. Choices were made using a choice apparatus (designed by Salwiczek et al., 2012), which consisted of two doors fastened by Velcro, attached to each other by a string that worked in a drawbridge-like fashion; that is, one door pulled closed when the other was pushed open. In the Free Choice condition (left), the two objects were located within reach of the model, while in the Limited Choice condition (right), only one object was within reach, so the subject was forced to choose this object. Neither trapdoor was ever blocked regardless of condition.

All subjects were tested in both conditions. Subjects from the same social group were tested on the same condition at the same time, though the initial condition was counterbalanced across groups. Each object was used twice, but always in different pairs so that neither the focal nor the model subjects ever saw the same combination twice. To prevent subjects from making a choice based simply on the side that the model chose, the side of each object presented to the focal subject changed in each trial (the order presented to the model subject remained the same for the focal subject in half of the trials and different in the other half, so that half of the time the same object was on the same side and half of the time it was on the opposite side).

All four subjects in Group A first played both model and focal subject in 12 trials in the Free Choice condition (for a total of 48 trials; for details on data, see Supplemental Material), while all six subjects in Group B first played each role in 10 trials in the Limited Choice condition (for a total of 60 trials). Note that subjects in Group B received overall fewer trials than in Group A, because one individual (Gambit) ceased returning the objects reliably to the experimenter. Consequently, we decided to stop testing this group in this condition in order to keep exposure to the task consistent across subjects, and to use the individual who ceased returning the objects only as a model in subsequent testing. After being tested in one condition, each group was given one series of the other condition, so that the total number of trials per condition (both groups included) was approximately the same. This low trial number was to reduce subjects' exposure to the task. To summarize, all four subjects in Group A played each role in six sessions in the Limited Choice condition (for a total of 24 trials). In Group B, because one subject (Gambit) was used only as model, the other five subjects played the model subject in four trials and the focal subject in six trials in the Free Choice condition (for a total of 30 trials).

\section{Statistics}

We conducted three analyses in this study. We first used a two-tailed exact binomial test to compare whether the focal subjects chose the same or different object as the model subjects in each condition. As there were too few data points for an individual analysis, we looked at subjects' combined performance in each social group separately (to control for order effects). Second, we compared 
monkeys' performance between the two conditions, using the subject's choices in the Free Choice condition as the baseline for how often subjects chose the same object in the task. Third, we looked at whether subjects preferentially chose PVC or metallic objects (we did not have enough data points to repeat the above analyses using all-PVC or all-metallic combinations). For this, we used data from both focal subjects and model subjects in the Free Choice condition (recall that the model was not trained, so their choices presumably represented their preferences, but they could not choose between objects in the Limited Choice condition). All reported statistics are two-tailed.

\section{Results}

Overall, focal subjects did not show a significant preference for one object over the other in either the Free Choice condition (two-tailed exact binomial test, $N=77, p=.254$; see Table 1) or the Limited Choice condition $(N=84, p=.445)$. Because of the intentionally low number of trials overall, at the individual level, there were no differences in preference for either object of the pair (all $p \mathrm{~s}>.05$ ).

When comparing performance across conditions, subjects as a group chose the same object as the model in 44 of the 77 trials; that is, $57 \%$ of the time (Table 1). Using this value as the baseline level representing the extent to which individuals copy the model in this paradigm, we calculated the binomial score of subjects' performance in the Limited Choice condition. Subjects chose the different object significantly more often than the same object in the Limited Choice condition (two-tailed exact binomial test, $N=84, p=.040$ ). This trend was evidenced for 7 out of 9 monkeys (calculating the proportion of different trials across conditions). Monkeys also chose PVC objects significantly more often than metallic objects; they selected the PVC object in 145 and the metallic one in 93 out of the 238 trials in which they were choosing between the two (two-tailed exact binomial test, $p=.001$ ).

Table 1

Focal Subjects' Choices of the Same or Different Object as the Model Subjects in each Condition in Study 1.

\begin{tabular}{|c|c|c|c|c|c|}
\hline \multirow[t]{2}{*}{ Subject } & \multirow[t]{2}{*}{ Group } & \multicolumn{2}{|c|}{ Free } & \multicolumn{2}{|c|}{ Limited } \\
\hline & & same & different & same & different \\
\hline Griffin & $\mathrm{A}$ & 7 & 5 & 3 & 3 \\
\hline Lily & $\mathrm{A}$ & 6 & 6 & 2 & 4 \\
\hline Wren & A & 7 & 5 & 1 & 5 \\
\hline Drella & A & 5 & 7 & 3 & 3 \\
\hline Gabe & B & 4 & 2 & 6 & 4 \\
\hline Nkima $^{1}$ & B & 3 & 2 & 2 & 8 \\
\hline Liam & B & 3 & 3 & 6 & 4 \\
\hline Logan & B & 4 & 2 & 7 & 3 \\
\hline Nala & B & 5 & 1 & 4 & 6 \\
\hline Gambit & $\mathrm{B}$ & - & - & 4 & 6 \\
\hline Total trials & & 44 & 33 & 38 & 46 \\
\hline
\end{tabular}

${ }^{1}$ Subject received fewer trials in the Free Choice condition, because the partner (Gambit) did not return the object to the experimenter in trial 1 .

\section{Discussion}

Focal subjects were not significantly more likely to choose the same (or different) objects as the model subjects in either condition when compared to chance $(50 \%)$. However, when using the Free Choice condition as an index for estimating the likelihood that subjects would copy the focal animal's choice in this paradigm, the results of the Limited Choice paradigm suggest they are more likely to select the different object. Of course, we cannot know whether they were actively avoiding the same choice as the model (which they did not do in the Free Choice condition) or were choosing the different object because the fact that it was out of reach of the model drew their attention to it and/or made it more salient. Nonetheless, subjects did show a significant change in choice in this condition, as compared to the Free Choice condition. 
Monkeys also chose the PVC objects more than the metallic ones. Although both metal and PVC are materials the monkeys frequently encounter (their housing and enrichment is made of both materials), the PVC tokens were more similar in form to experimental tokens used routinely in our lab (e.g., Brosnan et al., 2011; Evans et al., 2012), which may explain their preference. Unfortunately, this preference for PVC could mean that their preference for certain materials overrode any preference based on their partner's choice.

Therefore, in order to tease these two factors apart, for our next study (Study 2), we conducted the same experiment but used only objects made of PVC that varied in color and pattern. It was essential to include pattern as well as color as capuchin males and many capuchin females are dichromats (i.e., missing the red-green cone), and so may not perceive differences in color sufficiently well for a discrimination task (see Gomes, Pessoa, Tomaz, \& Pessoa, 2002; Jacobs, 2007; although see evidence in Parrish, Brosnan, \& Beran, 2015, suggesting that they generally have no difficulty with color discrimination tasks).

\section{Study 2}

\section{Procedure}

The basic procedure was the same as in Study 1, except that the objects were differently colored/patterned PVC token pipes. The combinations were designed to be easy to distinguish, so that in each pair there was a patterned and a solid token, and one of these was always a darker color than the other (see Figure 4). As in Study 1, subjects played both the role of model and focal and we tested all possible combinations of pairs. Again, we looked at whether the focal subject chose the same or the different object as the model subject. To see whether the focal subjects were watching the partner during the demonstration, we also video-recorded the trials and coded the subjects' location and body orientation during the actual choice (see below).

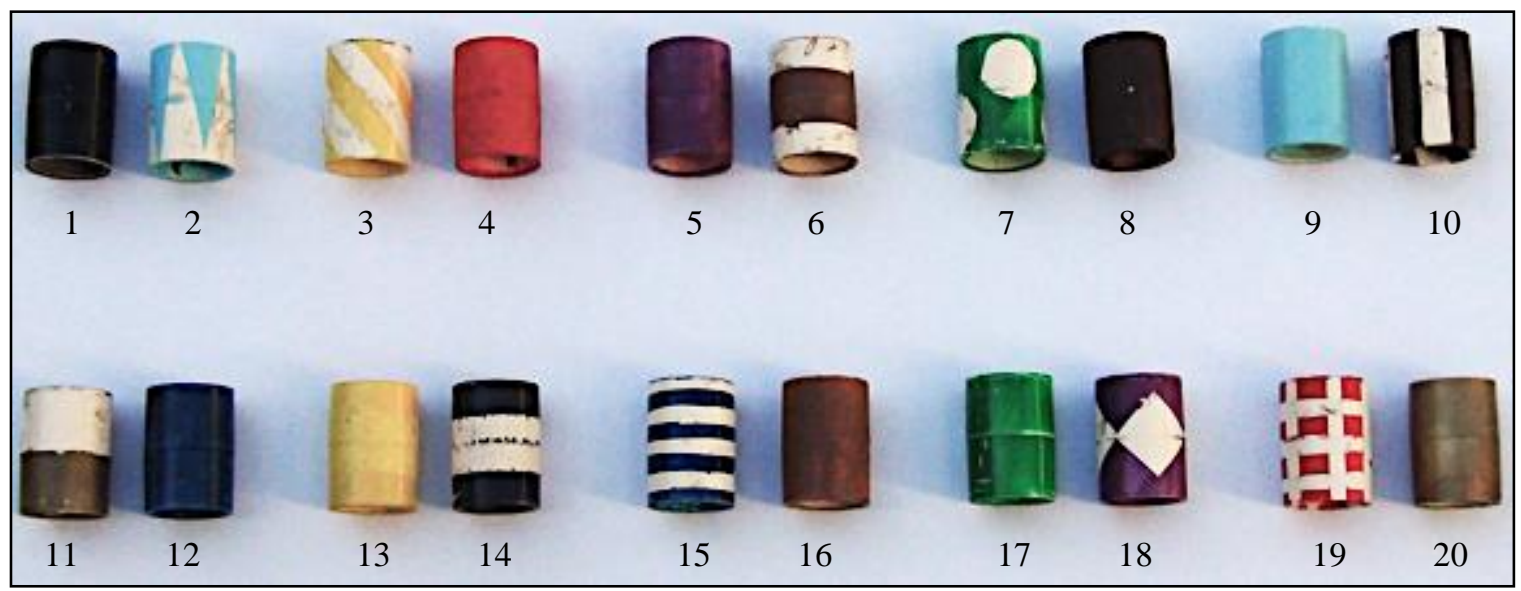

Figure 4. Set of PVC tokens used in Study 2. Note that each pair (1-2, 3-4, 5-6, 7-8, 9-10, 11-12, 13-14, 15-16, 17-18, 19-20) was made of a patterned and a solid token, and one of these was always a darker color than the other.

The two monkey groups were each tested with 10 unique pairs of tokens in both the Free Choice and the Limited Choice conditions. Group A was first tested on the Free Choice condition (for details on data, see Supplemental Material), while Group B was first tested on the Limited Choice condition. Each group was then given one series of the other condition. One subject from Study 1 (Drella) died of congestive heart failure before Study 2 commenced, resulting in a sample size of three individuals for Group A. Because of the uneven number of subjects for pairing in this group, two subjects (Griffin and Wren) played both model and focal subject in three trials in each condition, while one subject (Lily) 
played both roles in four trials (for a total of 10 trials per condition). In Group B, the subject who did not return the objects reliably to the experimenter in Study 1 (Gambit) played only the role of model in all trials of Study 2, which is why the other subjects played the model in three trials and the focal in six trials in each condition (for a total of 30 trials per condition).

\section{Measure of Attention}

Each trial was recorded using a HDR-XR260V Sony camcorder, and later coded using a VLC media player. We recorded the subjects' location and body orientation to see whether focal subjects were 1) overall facing towards the model and 2) more so in one condition than the other. Our video camera was not sufficiently high in resolution to reliably determine eye gaze or head orientation as a measure of attention (e.g., see Itakura, 1996; Marsh, 2012; Tomasello, Hare, Lehman, \& Call, 2007). Nonetheless, it was of sufficient quality to determine whether the focal subject in principle could have seen the model's choice. For each trial recorded, we coded whether the focal subject 1) was located in the front quadrant of the subject's compartment that was adjacent to the partner's compartment and 2) was oriented towards the partner's choice at the moment the model picked up the selected token. Although these measures do not allow us to tell whether the subject was actually paying attention, or to what, we can at least discriminate when they could not have seen their partner's choice. Two people familiar with the testing subjects coded these behaviors. We then calculated Cohen's kappa $(k)$ for each behavior to test for interrater reliability (IRR). There was a substantial agreement between the two judgments for the location of the focal subject $(k=.893 ; p<0.001)$, with raters agreeing on 73 out of 75 trials $(97 \%$; see below for details on the number of trials coded), and also for the orientation of the focal subject $(k=.775 ; p<.001)$, with raters agreeing on 70 out of 75 trials $(93 \%)$.

\section{Results}

As in Study 1, the focal subjects did not show any preference for either object in either the Free Choice condition (two-tailed exact binomial test, $N=40, p=.636$; see Table 2) or the Limited Choice condition (although they showed a non-significant trend towards choosing the different object; $N=40, p$ $=.081$ ). When analyzing the performance of each social group, neither group showed any difference in preference for either object in the Free Choice condition (Group A, $N=10, p=.754$; Group B, $N=30, p$ $=.362)$; however, while Group A did not show any difference in the Limited Choice condition $(N=10, p$ $=1.000)$, Group B chose the different object significantly more often $(N=30, p=.043)$.

Table 2

Focal Subjects' Choices of the Same or Different Object as the Model Subjects in each Condition in Study 2.

\begin{tabular}{|c|c|c|c|c|c|}
\hline \multirow[t]{2}{*}{ Subject } & \multirow[t]{2}{*}{ Group } & \multicolumn{2}{|c|}{ Free } & \multicolumn{2}{|c|}{ Limited } \\
\hline & & same & different & same & different \\
\hline Griffin & $\mathrm{A}$ & 2 & 1 & 2 & 1 \\
\hline Lily & A & 3 & 1 & 2 & 2 \\
\hline Wren & $\mathrm{A}$ & 1 & 2 & 1 & 2 \\
\hline Gabe & B & 2 & 4 & 1 & 5 \\
\hline Nkima & B & 3 & 3 & 3 & 3 \\
\hline Liam & B & 3 & 3 & 1 & 5 \\
\hline Logan & B & 3 & 3 & 3 & 3 \\
\hline Nala & B & 1 & 5 & 1 & 5 \\
\hline Total trials & & 18 & 22 & 14 & 26 \\
\hline
\end{tabular}

As in Study 1, we also compared monkeys' performance between the two conditions using the Free Choice condition as the baseline for how often subjects chose the same object in the task. Subjects as a group preferred to choose the same object as the model in 18 of the 40 trials; that is, $45 \%$ of the time 
(Table 2). When using this value to calculate the binomial score of subjects' performance in the Limited Choice condition, we found that subjects did not choose the different object significantly more often than the same object in the Limited Choice condition (two-tailed exact binomial test, $N=40, p=.266$ ). When analyzing the performance of each social group, neither group showed any difference in preference for either object in the Limited Choice condition (Group A, $N=10, p=.992$; Group B, $N=30, p=.138$ ).

We used subjects' location in the cage and body orientation as a surrogate measure of whether they could have seen their partner's choice. We coded 76 of the 80 total trials (four trial videos were not recorded properly), but one trial was excluded because the focal subject was not sufficiently visible during the model's choice, resulting in 75 trials. Overall, the focal subject was located in the quadrant adjacent to the partner in 64 of the 75 trials $(85 \%)$, and was apparently oriented towards the partner's choice in 63 trials $(84 \%)$. When looking at the detailed results for each condition, the focal subject was located in the relevant quadrant in 31 of 37 trials $(84 \%)$ and oriented towards the choice in 30 trials $(81 \%)$ in the Free Choice condition, while the focal subject was located in the relevant quadrant and oriented towards the choice in 33 of 38 trials (87\%) in the Limited Choice condition.

\section{Discussion}

Although subjects did not show any preference in the Free Choice condition, one social group chose the different object significantly more often than the same object in the Limited Choice condition. Although the overall results of Study 2 were not as robust as those in Study 1, it is possible that the monkeys may have habituated to the paradigm (and, as noted in the methods, some monkeys served in the role as chooser multiple times).

\section{General Discussion}

In the current research, we used a novel paradigm to investigate whether nonhuman primates act on the basis of knowledge gained from watching volitional versus compulsory choices produced by conspecifics. In the task, a model subject could choose between two different objects while a focal subject watched, after which the focal was presented with the same choice. There were two conditions: in the Free Choice condition, the model chose freely between two objects that were placed within reach of the subject, while in the Limited Choice condition, only one of the two objects was within reach of the model, who was forced to select this object. We predicted that monkeys would copy the choice of the partner in the Free Choice condition, which we did not find. We also predicted that subjects would be more likely to show a preference for the same object as the model in the Free Choice condition than in the Limited Choice condition. Although we did not find this, we did find that subjects were more likely to choose the different option in the Limited Choice condition. These results indicate that they attended to their partner's choice and that their subsequent choices could be influenced by the situation in which their partner chose.

Subjects' overall preference for the different object in the Limited Choice condition is intriguing. Subjects seemed most attracted to what had been out of reach, though we are unclear as to why they exhibit this preference. It is possible that subjects are most attracted to what they perceive the experimenter is keeping for herself, perhaps assuming that it is a better option (e.g., West, Jett, Beckman \& Vonk, 2010). However, this explanation feels unsatisfying in light of all of the evidence from the social learning literature indicating that primates easily learn from watching a partner interact with objects (e.g., Bonnie \& de Waal, 2007; Brosnan \& de Waal, 2004). Perhaps a more plausible explanation is that the Limited Choice condition simply attracted their attention more because it was a novel situation for our monkeys. In most studies in our lab in which subjects are given a choice, it is at least in principle possible to obtain either option. Indeed, anecdotally, out-of-reach objects are fascinating to our monkeys, who will spend substantial time, energy, and ingenuity attempting to reach them.

The monkeys also showed an overall preference for the PVC objects relative to the metallic ones. This was potentially a confounding factor that would have hidden an effect of the model, so in an attempt 
to obtain stronger evidence of copying, in Study 2, we tested subjects using only PVC tokens. Our results in the Free Choice condition were not as robust as those in Study 1. Again, however, monkeys in one group still chose the different object in the Limited Choice condition, indicating that they adapted their behavior based on the partner's choice. It is possible the monkeys are not as likely to copy the partner when the object being chosen is inedible. Alternatively, the subjects may have habituated to the paradigm by the second study and so were no longer paying attention to or using this information. Although we tried to limit exposure, and used novel token pairs on each trial, subjects acted as both subjects and models. As a result, it may be that our results from Study 1 were more indicative of their choices before they realized that the choice did not lead to different outcomes. While our results demonstrate some evidence for volitional copying by capuchins, we recognize that these results were not as strong as anticipated. Below, we speculate on why our paradigm failed to elicit such robust copying, and consider what they may mean for experiments in cognitive and comparative psychology in general.

The weak effect found in the Free Choice condition may have been due to some aspects of our procedures. First, the task may not have elicited their attention. Although our video analysis indicates that they were oriented towards the partner, we can only infer attention from that measure. In particular, perhaps the lack of food during the trials lessened their interest; in most tasks in which subjects must watch their partner's choices, food is available at or around the time of the choice (Bonnie \& de Waal, 2007; Brosnan \& de Waal, 2004). In the future, we could use better means of tracking their attention (i.e., an eye-tracker, technology that is not currently available to us) or augment their attention by providing food. However, the latter option brings with it the risk that they choose based on the food (i.e., that they mistakenly infer that only the 'right' choice brings food), which is why we chose not to use it for this study.

Another important limitation to the current procedure is that, due to our small sample size, we were unable to investigate whether subjects' experience as demonstrators prior to being a focal subject influenced their performance in the task. For example, it is possible that having the experience of choosing freely between the two objects in the Free Choice condition, with no consequence, might have led subjects to make random choices in subsequent trials. Similarly, we had a small number of focal subjects (8-10; Tables 1 \& 2) and a small number of trials per subject in each condition (3-12; Tables 1 \& 2 ), so we had limited power. Consequently, it is possible that there was an effect that eluded detection. Our findings thus emphasize the challenges of small sample sizes, and hence reduced statistical power, when testing for social learning effects. Of course, this is an ever-present challenge in work on nonhuman species, which is why repeated studies of both successful and unsuccessful paradigms are important to validate previous results and determine the contexts and conditions under which a given behavior occurs.

The current special issue focuses on 'meaningful' failures in cognitive science. We are not sure that we meet either criterion. Our results weakly support our hypothesis, although they do not unequivocally demonstrate that the subjects' choices are influenced by watching their partner's decision. Is this a failure? We argue no, but clearly more work is needed on the topic. We hope that, like us, others will be willing to report 'messy' or surprising data in a joint effort to better understand cognition and behavior in nonhuman species.

\section{Acknowledgements}

We thank the staff at the Language Research Center of Georgia State University for making this study possible. L. P. was funded by a GSU Second Century Initiative in Primate Social Cognition, Evolution \& Behavior Dissertation Grant (2CI-PSCEB) at Georgia State University. D. J. W. was funded by the National Institutes of Health (R01 HD067250). S. F. B. was funded by the National Science Foundation (SES 1425216). 


\section{References}

Auersperg, A. M. I., von Bayern, A. M. I., Weber, S., Szabadvari, A., Bugnyar, T., \& Kacelnik, A. (2014). Social transmission of tool use and tool manufacture in Goffin cockatoos (Cacatua goffini). Proceedings of the Royal Society B, 281, 20140972.

Baldwin, D. A., Baird, J. A., Saylor, M. M., \& Clark, M. A. (2001). Infants parse dynamic action. Child Development, 72, 708-17.

Behne, T., Carpenter, M., Call, J., \& Tomasello, M. (2005). Unwilling versus unable: Infants' understanding of intentional action. Developmental Psychology, 41, 328-337.

Bonnie, K. E., \& de Waal, F. B. M. (2007). Copying without rewards: Socially influenced foraging decisions among brown capuchin monkeys. Animal Cognition, 10, 283-292.

Brosnan, S. F., \& de Waal, F. B. M. (2004). Socially learned preferences for differentially rewarded tokens in the brown capuchin monkey (Cebus apella). Journal of Comparative Psychology, 118, 133-139.

Brosnan, S. F., Parrish, A., Beran, M. J., Flemming, T., Heimbauer, L., Talbot, C. F.,..Wilson, B. J. (2011). Responses to the assurance game in monkeys, apes, and humans using equivalent procedures. Proceedings of the National Academy of Sciences of the USA, 108, 3442-3447.

Bugnyar, T., \& Kotrschal, K. (2004). Leading a conspecific away from food in ravens (Corvus corax)? Animal Cognition, 7, 69-76.

Burkart, J. M., Kupferberg, A., Glasauer, S., \& van Schaik, C. (2012). Even simple forms of social learning rely on intention attribution in marmoset monkeys (Callithrix jacchus). Journal of Comparative Psychology, 126, 129-138.

Buttelmann, D., Buttelmann, F., Carpenter, M., Call, J., \& Tomasello, M. (2017) Great apes distinguish true from false beliefs in an interactive helping task. PLOS ONE, 12: e0173793.

Buttelmann, D., Carpenter, M., Call, J., \& Tomasello, M. (2008). Rational tool use and tool choice in human infants and great apes. Child Development, 79, 609-626.

Call, J., \& Jensen, K. (2007). Chimpanzees may recognize motives and goals, but may not reckon on them. Empathy and Fairness: Novartis Foundation Symposium, 278, 56-70.

Call, J., \& Tomasello, M. (1998). Distinguishing intentional from accidental actions in orangutans (Pongo pygmaeus), chimpanzees (Pan troglodytes) and human children (Homo sapiens). Journal of Comparative Psychology, 112, 192-206.

Call, J., \& Tomasello, M. (1999). A nonverbal false belief task: The performance of children and great apes. Child Development, 70, 381-395.

Call, J., Hare, B., Carpenter, M., \& Tomasello, M. (2004). 'Unwilling versus 'unable’: Chimpanzees' understanding of human intentional action. Developmental Science, 7, 488-498.

Canteloup, C., \& Meunier, H. (2017). 'Unwilling' versus 'unable': Tonkean macaques' understanding of human goal-directed actions, PeerJ, 5:e3227.

Costes-Thiré, M., Levé, M., Uhlrich, P., Pasquaretta, C., Marco, A., \& Thierry, B. (2015). Evidence that monkeys (Macaca tonkeana and Sapajus apella) read moves, but no evidence that they read goals. Journal of Comparative Psychology, 129, 304-310.

de Waal, F. B. M., \& Bonnie, K. E. (2009). In tune with others: The social side of culture. In K. Laland \& B. G. Galef (Eds.), The question of animal culture, (pp. 19-40). Cambridge, MA: Harvard University Press.

Dindo, M., Thierry, B., \& Whiten, A. (2008). Social diffusion of novel foraging methods in capuchin monkeys (Cebus apella). Proceedings of the Royal Society B, 275, 187-193.

Dindo, M., Whiten, A., \& de Waal, F. B. M. (2009). In-group conformity sustains different foraging traditions in capuchin monkeys (Cebus apella). PLoS ONE, 4: e7858.

Drayton, L. A., \& Santos, L. (2014) Capuchins' (Cebus apella) sensitivity to others' goal-directed actions in a helping context. Animal Cognition, 17, 689-700.

Drayton, L. A., Varman, L., \& Santos, L. R. (2016). Capuchins (Cebus apella) are limited in their ability to infer others' goals based on context. Journal of Comparative Psychology, 130, 71-75.

Emery, N. J., Lorincz, E. N., Perrett, D. I., Oram, M. W., \& Baker, C. I. (1997). Gaze following and joint attention in rhesus monkeys (Macaca mulatta). Journal of Comparative Psychology, 111, 286-293.

Evans, T. A., Beran, M. J., Paglieri, F., \& Addessi, E. (2012). Delaying gratification for food and tokens in capuchin monkeys (Cebus apella) and chimpanzees (Pan troglodytes): When quantity is salient, symbolic stimuli do not improve performance. Animal Cognition, 15, 539-548.

Fragaszy, D., Visalberghi, E., \& Fedigan, L. M. (2004). The complete capuchin: The biology of the genus Cebus. Cambridge, UK: Cambridge University Press. 
Gergely, G., Bekkering, H., \& Kiraly, I. (2002). Rational imitation in preverbal infants. Nature, 415, 755.

Gergely, G., Nadasdy, Z., Csibra, G., \& Biro, S. (1995). Taking the intentional stance at 12 months of age. Cognition, 56, 165-193.

Gomes, U., Pessoa, D. M. A., Tomaz, C., \& Pessoa, V. F. (2002). Color vision perception in the capuchin monkey (Cebus apella): A re-evaluation of procedures using Munsell papers. Behavioural Brain Research, 129, $153-157$.

Hare, B., Call, J., Agnetta, B., \& Tomasello, M. (2000). Chimpanzees know what conspecifics do and do not see. Animal Behaviour, 59, 771-785.

Hopper, L. M., Lambeth, S. P., Schapiro, S. J., \& Whiten, A. (2015). The importance of witnessed agency in chimpanzee social learning of tool use. Behavioural Processes, 112, 120-129.

Itakura, S. (1996). An exploratory study of gaze-monitoring in nonhuman primates. Japanese Psychological Research, 38, 174-180.

Jacobs, G. H. (2007). New World monkeys and color. International Journal of Primatology, 28, 729-759.

Kaminski, J., Call, J., \& Tomasello, M. (2008). Chimpanzees know what others know, but not what they believe. Cognition, 109, 224-234.

Krachun, C., Carpenter, M., Call, J., \& Tomasello, M. (2009). A competitive nonverbal false belief task for children and apes. Developmental Science, 12, 521-535.

Krachun, C., Carpenter, M., Call, J., \& Tomasello, M. (2010). A new change-of-contents false belief test: Children and chimpanzees compared. International Journal of Comparative Psychology, 23, 145-165.

Krupenye, C., Kano, F., Hirata, S., Call, J., \& Tomasello, M. (2016). Great apes anticipate agents' actions based on their false beliefs. Science, 354, 110-114.

Kupferberg, A., Glasauer, S., \& Burkart, J. M. (2013). Do robots have goals? How agent cues influence action understanding in nonhuman primates. Behavioural Brain Research, 246, 47-54.

Marsh, H. L. (2012). Orangutans' use of contiguous versus distal social and non-social cues in an object choice task. International Journal of Comparative Psychology, 25, 299-308.

Marshall-Pescini, S., Ceretta, M., \& Prato-Previde, E. (2014). Do domestic dogs understand human actions as goaldirected? PLoS ONE, 9: e106530.

Parrish, A. E., Brosnan, S. F., \& Beran, M. J. (2015). Capuchin monkeys alternate play and reward in a dual computerized task. Animal Behavior and Cognition, 2, 334-347.

Péron, F., Rat-Fischer, L., Nagle, L., \& Bovet, D. (2010). 'Unwilling' versus 'unable': Do grey parrots understand human intentional actions? Interaction Studies, 11, 428-441.

Perry, S. (2011). Social traditions and social learning in capuchin monkeys (Cebus). Philosophical Transactions of the Royal Society B, 366, 988-996.

Phillips, W., Barnes, J. L., Mahajan, N., Yamaguchi, M., \& Santos, L. R. (2009). 'Unwilling' versus 'unable': Capuchins' (Cebus apella) understanding of human intentional action. Developmental Science, 12, 938945.

Povinelli, D. J., Perilloux, H. K., Reaux, J. E., \& Bierschwale, D. T. (1998). Young and juvenile chimpanzees’ (Pan troglodytes) reactions to intentional versus accidental and inadvertent actions. Behavioural Processes, 42, 205-218.

Premack, D., \& Woodruff, G. (1978). Does the chimpanzee have a theory of mind? Behavioral and Brain Sciences, 4, 515-526.

Reader, S. M., Hager, Y., \& Laland, K. N. (2011). The evolution of primate general and cultural intelligence. Philosophical Transactions of the Royal Society B, 366, 1017-1027.

Rosati, A., Hare, B. A., \& Santos, L. R. (2010). Primate social cognition: Thirty years after Premack and Woodruff. Primate Neuroethology, 1, 117-144.

Salwiczek, L. H., Prétôt, L., Demarta, L., Proctor, D., Essler, J., Pinto, A. I.,...Bshary, R. (2012). Adult cleaner wrasse outperform capuchin monkeys, chimpanzees and orang-utans in a complex foraging task derived from cleaner-client reef fish cooperation. PLOS ONE, 7: e49068.

Tomasello, M., \& Call, J. (1997). Primate cognition. Oxford, UK: Oxford University Press.

Tomasello, M., Call, J., \& Hare, B. (1998). Five primate species follow the visual gaze of conspecifics. Animal Behaviour, 55, 1063-1069.

Tomasello, M., Call, J., \& Hare, B. (2003). Chimpanzees understand psychological states: The question is which ones and to what extent. Trends in Cognitive Science, 7, 153-156.

Tomasello, M., Carpenter, M., Call, J., Behne, T., \& Moll, H. (2005). Understanding and sharing intentions: The origins of cultural cognition. Behavioral and Brain Sciences, 28, 675-735. 
Tomasello, M., \& Haberl, K. (2003). Understanding attention: 12- and 18-month-olds know what is new for other persons. Developmental Psychology, 39, 906-912.

Tomasello, M., Hare, B., Lehman, H., \& Call, J. (2007). Reliance on head versus eyes in the gaze following of great apes and humans: The cooperative eyes hypothesis. Journal of Human Evolution, 52, 314-320.

Visalberghi, E., \& Addessi, E. (2000). Seeing group members eating a familiar food enhances the acceptance of novel foods in capuchin monkeys. Animal Behaviour, 60, 69-76.

Visalberghi, E., \& Addessi, E. (2001). Acceptance of novel foods in Cebus apella: Do specific social facilitation and visual stimulus enhancement play a role? Animal Behaviour, 62, 567-576.

West, S., Jett, S. E., Beckman, T., \& Vonk, J. (2010). The phylogenetic roots of cognitive dissonance. Journal of Comparative Psychology, 124, 425-432.

Wood, J. N., Glynn, D. D., Phillips, B. C., \& Hauser, M. (2007). The perception of rational, goal-directed action in nonhuman primates. Science, 317, 1402-1405.

Woodward, A. L. (1998). Infants selectively encode the goal object of an actor's reach. Cognition, 69, 1-34.

Woodward, A. L. (1999). Infants' ability to distinguish between purposeful and non-purposeful behaviors. Infant Behavior and Development, 22, 145-160. 